\title{
Effects of negative social information on the willingness to support charities: the moderating role of regulatory focus
}

\author{
Nhat Quang Le ${ }^{1}$ (D) Magne Supphellen ${ }^{2} \cdot$ Richard P. Bagozzi $^{3}$
}

Published online: 9 September 2020

(C) The Author(s) 2020

\begin{abstract}
Donation campaigns that have an unsuccessful start often trigger negative social information in the social and mass media (e.g., "few others have donated so far"). Little research exists to shed light on the effects of such information in the context of donations. Across three studies involving different causes and different channels of communication, we find harmful effects of negative social information on the willingness to donate among prevention-focused consumers but tendencies of positive effects for consumers with a promotion focus. We identify response efficacy as a mediator of the harmful effect for prevention-focused consumers. This finding suggests that social proof theory is not sufficient to explain the harmful effect of negative social information. Alternative mediators are tested and rejected. The findings imply that an effective strategy to avoid harmful effects of negative social information is to trigger a promotion focus in target group members and communicate facts about charity effectiveness.
\end{abstract}

Keywords Willingness to donate - Donation behaviors · Social information · Response efficacy $\cdot$ Charities

\section{Introduction}

The competition for private donations is fierce, and the efforts of charities to mobilize stakeholders often fail (e.g., Bielefeld 2014). Social and mass media reports on such

Electronic supplementary material The online version of this article (https://doi.org/10.1007/s11002-020$09540-w)$ contains supplementary material, which is available to authorized users.

Nhat Quang Le

nhat.le@nh.no

Magne Supphellen

magne.supphellen@nhh.no

Richard P. Bagozzi

bagozzi@umich.edu

Extended author information available on the last page of the article 
failures typically contain negative social information, such as "few have donated so far" or "the response has been slow." For instance, the Canadian Broadcasting Corporation $(C B C)$ reported in 2014 that "donations were slow" for the annual Moncton Christmas holiday charity campaigns (CBC News 2014). The Intelligencer reported in October 2018: "The local United Way campaign is only a month old, but already it's lagging behind that of last year, when the charity failed to meet its fundraising goal for the second consecutive year" (Hendry 2018). Both reports reveal negative information about the behavior of other people: few others have donated.

The question is how such information may influence the willingness to donate. A large number of studies show that positive social information (that many have donated) may increase the willingness to support good causes (e.g., Croson et al. 2009; ElgaaiedGambier et al. 2018), but we know less about the effects of negative social information. There is certainly a risk that such information may keep donations low and prevent slow-starting campaigns from gaining momentum. However, we suggest a more nuanced picture and hypothesize that the regulatory focus of consumers moderates the effects of negative social information on their willingness to donate. We address these issues in three experiments.

Across three studies involving different types of charities and communication channels, we only observe negative effects of negative social information (few have donated) on the willingness to donate for prevention-focused consumers, whereas promotion-focused consumers tend to increase their willingness to donate when exposed to the information that few have donated. We show that the psychological mechanism driving the harmful effect for prevention-focused consumers is special to our donation context. The effect is not due to social norms per se but to doubts about response efficacy. Finally, we show in the third study that managers can influence the effect of negative social information on the willingness to donate by manipulating the consumers' regulatory focus. The results have important implications for the design of strategies on how to avoid harmful consequences of negative social information.

\section{Social information, regulatory focus, and willingness to donate: hypotheses}

The typical behavior of others represents social norms. According to the principle of social proof, people tend to follow social norms, assuming that this is the right course of action (Cialdini 2013). The effects of social norms on charitable behavior have received limited attention (Agerström et al. 2016), but the few studies addressing this issue show strong effects. For instance, Agerström et al. (2016) found that exposing students to positive descriptive social norms (i.e., that $73 \%$ of students have contributed previously) triggered higher donations than "industry standard" altruistic appeals, such as "Your gift makes a difference" or "By contributing you will improve living conditions for the children of Gossace School and orphanage." Based on these findings, we might expect that negative social information (that few have donated) would be very harmful to charities. However, we suggest that the effect of negative social information on the willingness of consumers to donate depends on their regulatory focus. We also expect that the regulatory focus of consumers will influence consumer decisions in a special way in our donation context. 
Regulatory focus theory (Higgins et al. 1994) describes two fundamental ways in which people approach goals: prevention focus and promotion focus. People with a promotion focus are more sensitive to the presence of positive outcomes (gains), fixating more on accomplishments, attainment, advancement, and personal aspirations, whereas people with a prevention focus are more sensitive to the presence of negative outcomes (losses) and are therefore more concerned with caution, protection, safety, and responsibilities (Higgins 1997). Although both promotion- and prevention-focused motivations coexist within each individual, people are often more chronically prone to access one focus over another (Higgins et al. 1994). Regulatory focus is a relevant moderator in our context because recent research suggests that it affects how prospective donors form goals based on social information (e.g., Allen et al. 2018).

We expect that negative social information will primarily harm the willingness to donate among prevention-focused consumers. This group is cautious to avoid negative outcomes and the information that few have donated will likely reduce their motivation to donate. This logic is similar to explanations for effects of prevention orientation in other contexts, such as consumption or investments decisions. However, we suggest that the psychological mechanism is different in a donation context. In other contexts, social information activates thoughts in prevention-focused consumers about social norms. The behavior of others is regarded as social proof of the appropriate course of action, which in turn affects behavior (Cialdini 2013). However, a unique aspect of our donation context is that the uncertainty that consumers experience relates closely to the capabilities of the charity. Charities act as intermediaries between donors and beneficiaries, and the risk of making a bad decision is due to the ability of the charity to operate effectively and complete its missions on behalf of donors. Thus, we predict that negative social information will not only activate social norms in our context, but these norms will, in turn, influence perceptions of response efficacy (Sharma and Morwitz 2016). Prevention-oriented consumers, who focus on avoiding negative outcomes, may use the information that few have donated as a cue for low response efficacy and thus lower their willingness to donate.

In contrast, promotion-oriented consumers do not focus on the risk of loss. They look for opportunities for gain and for positive self-enhancement (Higgins 1997). Their response to negative social information is probably different from that of preventionoriented consumers. When promotion-focused customers are exposed to negative social information (few have donated), this stimulates or primes their need for uniqueness. The higher need for uniqueness in turn increases the willingness to donate. Promotionfocused customers, as opposed to prevention-focused customers, satisfy their needs for self-enhancement (Baumeister 2010) and self-verification (Leary 2007) to the extent that they seek uniqueness, and willingness to donate promotes such need satisfaction. Prevention-focused customers are more motivated to protect their current self-image rather than enhancing or verifying it as promotion-focused customers do.

We propose the following hypotheses:

- H1: The effect of negative social information (that few have donated) depends on the self-regulation of consumers. Specifically, such information (a) lowers the willingness of prevention-focused consumers to support a new charity and (b) stimulates the willingness of promotion-focused consumers to support a new charity. 
- H2: Response efficacy mediates the harmful effect of negative social information (few have donated) on prevention-focused consumers' willingness to donate. Specifically, exposure to negative social information reduces response efficacy, which in turn lowers the willingness to donate.

- H3: Need for uniqueness mediates the positive effect of negative social information (few have donated) on promotion-focused consumers' willingness to donate. Specifically, exposure to negative social information strengthens the need for uniqueness, which in turn increases the willingness to donate.

\section{Tests of hypotheses}

In Study 1, we tested whether the consumers' regulatory focus moderates the effect of negative social information on their willingness to support a charity $(\mathrm{H} 1)$. In Study 2, we examined the mediating role of response efficacy and need for uniqueness as underlying drivers of the effect of negative social information on willingness to donate ( $\mathrm{H} 2$ and $\mathrm{H} 3)$. Finally, in Study 3, we manipulated the regulatory focus and tested the interaction effect in the context of another donation.

\subsection{Study 1: interaction between social information and regulatory focus}

In this study, we aimed to test whether negative social information makes preventionfocused (promotion-focused) consumers less (more) likely to support a charity.

\subsubsection{Method}

Using Amazon Mechanical Turk (MTurk), we recruited 102 US participants (aged 1970 years, $M_{\text {age }}=33$ years, $41.18 \%$ female) who took part in the study in exchange for $\$ 2$. They were randomly assigned to one of the two conditions (many had donated/few had donated). We first presented the participants with a short excerpt from the middle pages of a fictitious newspaper and asked them to focus on a short article about a new charity serving legal immigrant and refugee communities in the US. Social information is likely more diagnostic for new than for established charities. We included a general description of the charity's primary activities and a newly launched start-up fund. Participants then read a passage that contained the manipulation of social information: "few (many) people have donated to the charity so far." The manipulation also appeared in the heading, as shown in the online appendix. We then measured the participants' willingness to donate to the charity using a single-item scale (adapted from Bennett et al. (2013)). A six-item dominant regulatory focus scale (adapted from Mishra et al. (2010)) was used to measure the donors' self-regulation. Higher average scores indicate that participants were dominated by a prevention focus, whereas lower average scores indicate the domination of a promotion focus. We also collected information on age, gender, household income, marital status, and ethnicity (see online appendix for measures). Responses to an open question at the end about the purpose of the study showed that no participants correctly predicted our hypotheses. 


\subsubsection{Results}

Hypothesis testing We conducted an ANCOVA on the participants' willingness to support the charity. Our predictors included social information (few vs. many), meancentered regulatory focus, and their interaction. Income and ethnicity were included as control variables. Only income had a marginally significant effect $(F(6,87)=2.15$, $p=.06)$, while the effect of ethnicity was not significant $(p>.10)$. No main effects of social information and regulatory focus emerged. However, as expected, the interaction between negative social information and regulatory focus was significant $(F(1,87)=$ $4.02, p<.05)$. Using the Johnson-Neyman floodlight technique, our analysis shows that the negative effect of social information is significant only when the regulatory focus scores are greater than or equal to $.64\left(\mathrm{~B}_{\mathrm{JN}}=-.86, \mathrm{SE}=.43\right)$, meaning that dominantly prevention-focused respondents are less willing to support the charity when exposed to negative (compared to positive) social information $\left(\mathrm{M}_{\mathrm{few}} \leq 3.39, \mathrm{M}_{\text {many }} \geq 4.25\right.$, $p<.05$ ) (see Fig. 1). Thus, H1a is supported. In contrast, the effect of negative social information becomes positive $\left(\mathrm{B}_{\mathrm{JN}}=50.60, \mathrm{SE}=25.46\right)$ for participants with lower regulatory focus scores (i.e., dominantly promotion-focused), but it is not significant. Therefore, the trend is in line with $\mathrm{H} 1 \mathrm{~b}$, but the effect does not reach statistical significance.

We further tested the effects of regulatory focus on each type of social information. When presented with the information that few had donated, the dominant regulatory focus had a significant, negative effect $(\beta=-.52, p=.03)$, indicating that participants with a dominant prevention focus were less likely to support the charity than those with a dominant promotion focus. In contrast, when presented with the information that many had donated, the effect of dominant regulatory focus was positive but not significant $(\beta=.12, p=.70)$, indicating that people with different regulatory foci reacted similarly to positive social information (i.e., that many had donated).

In sum, our findings support the prediction that the effect of negative social information depends on the regulatory focus of consumers. We found that negative social information reduced willingness to donate among prevention-focused consumers

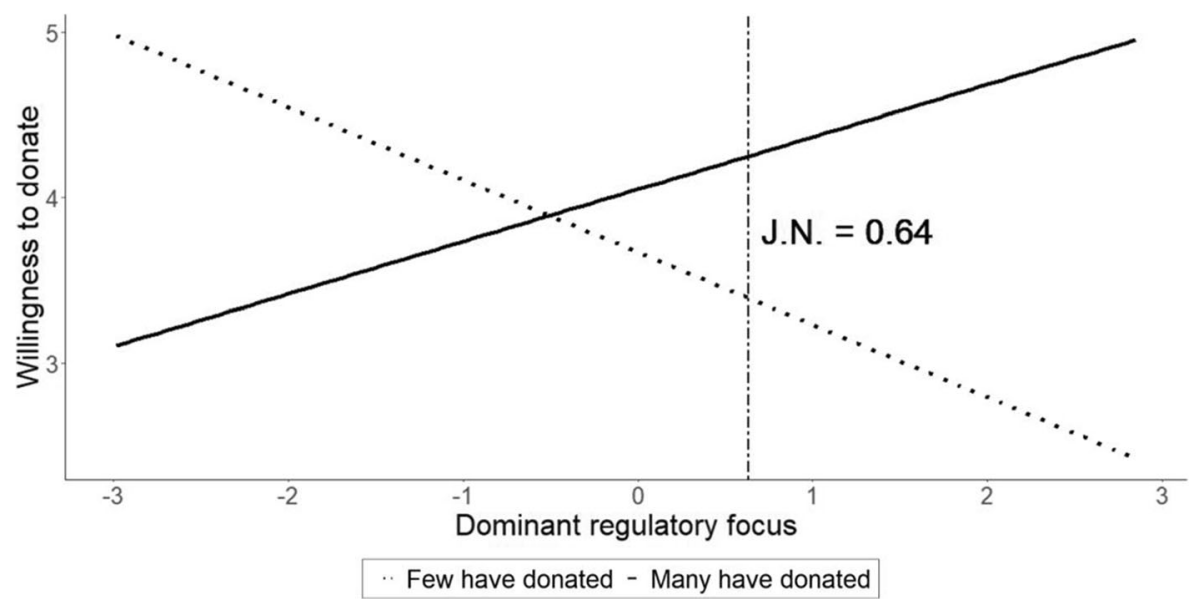

Fig. 1 Study 1: The interaction of dominant regulatory focus and social information 
(H1a). The expected positive effect of negative social information for promotionfocused consumers (H1b) was not significant.

\subsection{Study 2: the mediating roles of response efficacy and need for uniqueness}

The purpose of Study 2 was threefold: (1) to replicate the tests of H1a and H1b with other control variables, (2) to test $\mathrm{H} 2$ and $\mathrm{H} 3$ about the mediating effects of response efficacy and need for uniqueness, and (3) to test alternative control variables. Reasonable control candidates were feelings of guilt (e.g., Bennett et al. 2013; Xie and Bagozzi 2014), perceived need for donations (Lee et al. 2014), and perceived credibility of the charity (Newell and Goldsmith 2001). These variables are known to influence donors' reactions to charity information.

\subsubsection{Method}

In total, 122 US participants were recruited online via MTurk (aged 23-68 years, $\mathrm{M}_{\text {age }}=36$ years, $49.18 \%$ female), and the participants completed a two-group (social information: many had donated vs. few had donated) between-subjects study in exchange for $\$ 2$. The manipulation of social information was the same as that in Study 1 . The dependent variable was measured using a 5-item willingness-to-support scale (Bennett et al. 2013). To measure the regulatory focus, we used the same scale as in Study 1. We also measured response efficacy (Cryder et al. 2013), need for uniqueness (Lynn and Harris 1997), consumer guilt (Bennett et al. 2013), perceived need (Lee et al. 2014), and perceived credibility of the charity (Newell and Goldsmith 2001). Additionally, we controlled for money and time scarcity to avoid budget/time constraint effects (Liu and Aaker 2008) and collected information on age, gender, income, and ethnicity.

\subsubsection{Results}

Hypothesis testing We conducted an ANCOVA on the participants' willingness to support with negative social information dummy, mean-centered regulatory focus, and their interaction as predictors. We controlled for income, money scarcity, time scarcity, ethnicity, and perceived credibility. Only perceived credibility had a significant positive effect $(F(1,104)=61.97, p<.01)$, while the effects of other covariates were not significant ( $\mathrm{ps}>.10)$. As in Study 1, we found a significant interaction effect of negative social information and dominant regulatory focus $(F(1,104)=4.38, p=.04)$ (Fig. 2). We also observed that respondents provided with the information that few (vs. many) had donated were less likely to support the charity (negative effect: $\mathrm{B}_{\mathrm{JN}}=-.52$, $\mathrm{SE}=.26$; group means: $\mathrm{M}_{\text {few }} \leq 2.84, \mathrm{M}_{\text {many }} \geq 3.36, p<.05$ ) when their dominant selfregulation was prevention-focused (regulatory focus scores $\geq .43$ ). Thus, H1a is again supported in Study 2. We also observed the tendency of promotion-focused respondents being positively affected $\left(\mathrm{B}_{\mathrm{JN}}=5.55, \mathrm{SE}=2.80\right)$, but again this effect is not significant, rejecting $\mathrm{H} 1 \mathrm{~b}$.

We tested $\mathrm{H} 2$ on the role of response efficacy as a mediator of the negative effect for prevention-focused consumers using the bootstrapping method with 10,000 bootstrap 
iterations, which was run by the Process Macro for SPSS (model 8; Hayes and Little 2018). We also tested whether negative social information stimulated the need for uniqueness among promotion-focused consumers, as predicted by H3. Though our prediction of a positive effect of negative social information for promotion-focused consumers did not reach the level of statistical significance (H1b), the tendency was in the right direction in both Studies 1 and 2. A preliminary test of the mechanism would be helpful for future research. Specifically, we examined whether response efficacy and need for uniqueness tended to mediate the interactive effect occurring between individual differences in regulatory focus and negative social information on individuals' willingness to donate. To test alternative explanations, we also included guilt and perceived need as parallel mediators.

As predicted, the interactive effect between negative social information and regulatory focus on response efficacy was marginally significant $(b=-.40, p=.08)$. Importantly, the indirect effect of negative social information on willingness to support the charity via response efficacy was strongly significant for people with a prevention focus (one SD above the mean; indirect effect: $-.76, p=.01$ ), while it was not significant for people with promotion focus (one SD below the mean; indirect effect: $-.14, p=.60)$. Thus, $\mathrm{H} 2$ is supported.

As expected, the main effect of negative social information on need for uniqueness was positive and significant $(b=.55, p=.03)$, while the main effect of (mean-centered) regulatory focus was negative and marginally significant $(b=-.31, p=.09)$, indicating that people with a promotion focus tend to have higher need for uniqueness when learning negative social information. However, the interaction between negative social information and regulatory focus did not have a significant effect on need for uniqueness $(b=-.20, p=.43)$. Thus, H3 is not supported.

Further, none of the alternative mediators were significant. In particular, the interaction between negative social information and regulatory focus did not contribute any significant effect on guilt $(b=-.36, p=.20)$ or perceived need $(b=-.30, p=.29)$.

We also tested if perceived credibility mediated the interactive effect between negative social information and regulatory focus on response efficacy (i.e., serial mediation) and willingness to support the charity (i.e., parallel mediation). Our results

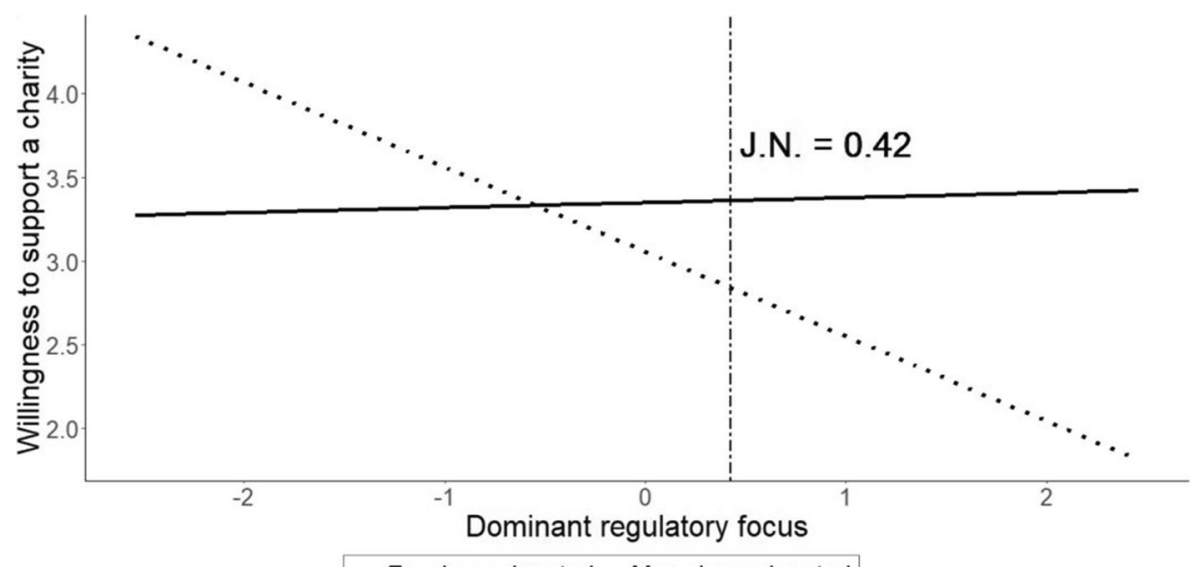

Few have donated - Many have donated

Fig. 2 Study 2: The interaction of dominant regulatory focus and social information 
revealed that this interactive effect on perceived credibility was not significant $(b=-.18, p=.56)$, meaning that perceived credibility was not a sound mediator. It is worth noting that the mediating effect of response efficacy remained significant when the mediating effects of guilt, perceived need, and perceived credibility were excluded. We can therefore rule out these three mediators as alternative explanations for the effects of social information.

\subsection{Study 3: manipulating regulatory focus}

In Study 3, we show that managers can influence the effect of negative social information on willingness to donate by manipulating the consumers' regulatory focus. We replicate the tests of $\mathrm{H} 1 \mathrm{a}$ and $\mathrm{H} 1 \mathrm{~b}$ using a different cause (animal welfare) and a new communication channel (Facebook). We also test another alternative explanation for our interactive effects: consumer innovativeness. The charities in our studies are new (fictitious), and it is possible that regulatory focus works as a proxy for consumer innovativeness.

\subsubsection{Method}

Using Prolific, we recruited 400 US participants (aged 18-73 years, $\mathrm{M}_{\text {age }}=39$ years, $46.75 \%$ female), who completed a 2 (social information: many had donated vs. few had donated) $\times 2$ (regulatory focus: prevention vs. promotion) between-subjects study in exchange for $\$ 1.12$. We asked the participants to imagine coming across a new post from the Facebook page of a new (fictitious) charity supporting animal welfare causes that they have just decided to follow. Following Allen et al. (2018), we manipulated people's regulatory focus by changing the wording in the appeals. In particular, the heading of the prevention-framed appeal was "PREVENT CRUEL TREATMENT OF ANIMALS" and the message stated, "Let's protect animals from unkind and cruel treatment." In the promotion-focus condition, the heading was "PROMOTE KIND TREATMENT OF ANIMALS" and the message stated, "Let's promote kind and respectful treatment of animals." We manipulated social information by informing participants that "too few (many) have pitched in so far (already)."

We measured willingness to support, perceived need, and perceived credibility of the charity using the same scales as in Study 2 and measured consumer innovativeness using a five-item scale adapted from Baumgartner and Steenkamp (1996). Additionally, we collected information on age, gender, income, and money/time scarcity.

\subsubsection{Results}

Manipulation check To check the regulatory focus manipulation (e.g., Aaker and Lee 2001), we asked the participants to rate the extent to which their thoughts, after reading the Facebook post, were focused on "preventing unkind and cruel treatment of animals" (prevention-related thoughts) or "promoting kind and respectful treatment of animals" (promotion-related thoughts). Our results revealed that participants in the preventionprimed condition exhibited more prevention-related thoughts $(M=5.25$ vs. 4.43, 
$p<.01)$ and less promotion-related thoughts $(\mathrm{M}=5.25$ vs. $4.10, p<.01)$ compared with the promotion-primed condition.

To check the social information manipulation (e.g., Allen et al. 2018), we asked the participants to indicate the extent to which they agreed that among the people who had received the donation request, the majority had donated to the charity. As expected, we found that people in the "few have donated" condition were less likely to agree that the charity had been supported by the majority $(M=1.87)$ than those in the "many have donated" condition $(\mathrm{M}=5.40, p<.01)$. Thus, the manipulations were successful.

Hypothesis testing We conducted an ANCOVA on the participants' willingness to support with negative social information dummy, prevention-focus dummy, and their interaction as predictors. We controlled for income, money scarcity, time scarcity, perceived credibility, perceived need, and consumer innovativeness. Only perceived credibility $(F(1,39)=182.31, p<.01)$ and perceived need $(F(1,390)=24.33, p<.01)$ had significant effects, while the effects of all other covariates were not significant (ps > .10). As in Studies 1 and 2, no main effects of negative social information or regulatory focus emerged, but we found a marginally significant interactive effect between them on respondents' willingness to support the charity $(F(1,390)=3.61$, $p=.06$ ) (Fig. 3).

Simple slopes analysis revealed the same pattern of results as in Studies 1 and 2. Respondents provided with the information that few (vs. many) had donated were less likely to support the charity $\left(\mathrm{M}_{\mathrm{Few}}=3.27, \mathrm{M}_{\mathrm{Many}}=3.61, b=-.33, p=.03\right)$ when they were primed for a prevention focus, confirming our H1a. Although we observed a tendency of a positive effect for promotion-focused respondents, this effect was not significant $\left(\mathrm{M}_{\mathrm{Few}}=3.46, \mathrm{M}_{\mathrm{Many}}=3.37, b=.09, p=.57\right)$, rejecting H1b. It is noteworthy that the patterns of results remained unchanged when innovativeness was excluded. This finding indicates that we can rule out consumer innovativeness as an alternative moderator of the effects of social information on individuals' willingness to support a charity.

\section{General discussion}

Our results offer three main theoretical contributions. First, we show across three studies, including different causes and channels of communication, that the downward risk of negative social information is limited to consumers with a prevention orientation. This group of consumers lowers the willingness to support when learning that few

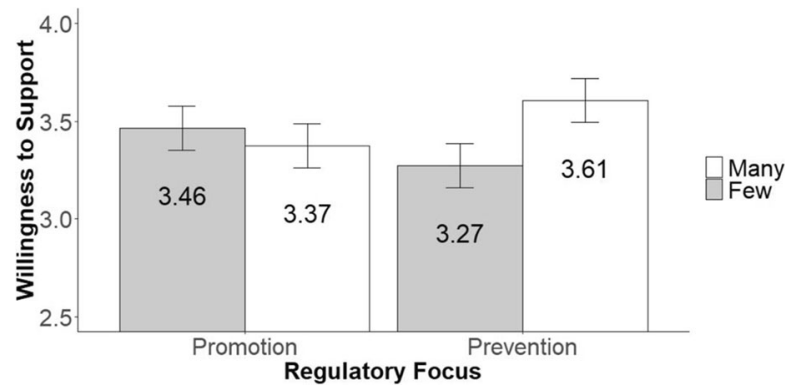

Fig. 3 Study 3: The interaction of regulatory focus and social information 
others have donated. In contrast, promotion-focused consumers tend to increase their support when exposed to the same situation, but this effect was not significant.

Second, we identify a mechanism behind the negative effect for prevention-focused consumers, which is different from mechanisms involving prevention-focused consumers in other economic contexts (e.g., product decisions, betting or investments, etc.). In other contexts, social information about the behavior of other people typically works as social proof of behavioral norms, which in turn guides decisions and behavior (e.g., Cialdini et al. 1990). In our donation context, it is not the social proof per se but the doubts about response efficacy triggered by negative social information that explain the harmful effect among prevention-focused consumers. Notably, if social proof was the main mechanism, then under positive social information (many have contributed), prevention-focused individuals should be more prone to give. We, however, did not find this effect. Thus, social proof theory seems less relevant in our context. Identifying response efficacy instead as the mechanism behind the negative effect for the prevention-focused consumers is important because the perception of response efficacy involves the capabilities of a charity.

Third, we test and reject three alternative explanations for the harmful effect of negative social information among prevention-focused consumers: moral emotions, perceived need, and the credibility of a charity. All three variables have played a role in previous research literature on donation behavior but are less relevant in our context, in which consumers respond to social information in mass or social media reports rather than to explicit requests to donate. We also show that regulatory focus does not work as a proxy for consumer innovativeness.

Our findings provide guidance for marketing managers on how to manage the risk of harmful effect of negative social information among prevention-focused consumers. First, when marketing managers of charities observe a slow start on a campaign, they should not hold back communications and wait for the campaign to gain traction. If social and mass media communicate that few have donated in a context that triggers a prevention focus, prospective donors may start to doubt the charity, and the campaign may never gain traction. Rather, marketing managers should actively promote the upward potential of such campaigns and use terms that trigger a promotion focus in target group members. In Study 3, we show that managers can easily trigger a promotion focus by encouraging consumers to "promote kindness" (rather than to "prevent cruelty"). Second, marketing managers should also communicate facts about the efficiency of the charity in this situation. Our findings suggest that the harmful effect of negative social information is due to doubts about response efficacy, which relates to the efficiency of a charity. A combination of cues triggering a promotionfocus and communication of positive facts about the efficiency of the charity may guard against harmful responses to negative social information and give slow-starting campaigns the opportunity to gain new momentum.

Several unanswered questions await future research. Across the three studies, we observed a (non-significant) tendency of positive effects of negative social information among promotion-focused consumers. More research is needed to understand how promotion-focused consumers respond to negative social information. We hypothesized that this group would consider the information that few had donated as an opportunity for social differentiation. Our results suggest that other mechanisms are (also) relevant. In this research, we examined the effects of social information on 
consumers' willingness to support new (fictitious) charities. Future research should compare the effects of negative social information for new and established charities. Well-known charities with a good reputation are probably less sensitive to the harmful effects of negative social information.

Funding Open Access funding provided by Norwegian School Of Economics. This study was financially supported by Norwegian School of Economics (NHH).

Availability of data and material Available at request.

\section{Compliance with ethical standards}

Conflict of interest/competing interests The authors declare that they have no conflict of interest.

Code availability Available at request

Open Access This article is licensed under a Creative Commons Attribution 4.0 International License, which permits use, sharing, adaptation, distribution and reproduction in any medium or format, as long as you give appropriate credit to the original author(s) and the source, provide a link to the Creative Commons licence, and indicate if changes were made. The images or other third party material in this article are included in the article's Creative Commons licence, unless indicated otherwise in a credit line to the material. If material is not included in the article's Creative Commons licence and your intended use is not permitted by statutory regulation or exceeds the permitted use, you will need to obtain permission directly from the copyright holder. To view a copy of this licence, visit http://creativecommons.org/licenses/by/4.0/.

\section{References}

Aaker, J. L., \& Lee, A. Y. (2001). "I" seek pleasures and "we" avoid pains: the role of self-regulatory goals in information processing and persuasion. Journal of Consumer Research, 28, 33-49.

Agerström, J., Carlsson, R., Nicklasson, L., \& Guntell, L. (2016). using descriptive social norms to increase charitable giving: the power of local norms. Journal of Economic Psychology, 52, 147-153.

Allen, A. M., Eilert, M., \& Peloza, J. (2018). How deviations from performance norms impact charitable donations. Journal of Marketing Research, 55, 277-290.

Baumeister, R. F. (2010). The self. Oxford university press.

Baumgartner, H., \& Steenkamp, J.-B. E. M. (1996). Exploratory consumer buying behavior: conceptualization and measurement. International Journal of Research in Marketing, 13, 121-137. https://doi.org/10.1016 /0167-8116(95)00037-2.

Bennett, C. M., Kim, H., \& Loken, B. (2013). Corporate sponsorships may hurt nonprofits: Understanding their effects on charitable giving. Journal of Consumer Psychology, 23, 288-300.

Bielefeld, W. (2014). The challenges of new profits. Nonprofit quarterly. https://nonprofitquarterly.org/thechallenges-of-new-nonprofits/. Accessed 1st Aug 2019.

CBC News (2014). Donations slow for Moncton holiday charity campaigns. CBC. https://www.cbc. ca/news/canada/new-brunswick/donations-slow-for-moncton-holiday-charity-campaigns-1.2866976. Accessed May 9th 2020.

Cialdini, R. B. (2013). Influence: science and practice (5th ed.). Harlow: Pearson Education.

Cialdini, R. B., Reno, R. R., \& Kallgren, C. A. (1990). A focus theory of normative conduct: recycling the concept of norms to reduce littering in public places. Journal of Personality and Social Psychology, 58, 1015-1026.

Croson, R. T. A., Handy, F., \& Shang, J. (2009). Keeping up with the joneses: the relationship of perceived descriptive social norms. Social Information, and Charitable Giving Nonprofit Management \& Leadership, 19, 467-489.

Cryder, C., Loewenstein, G., \& Scheines, R. (2013). The donor is in the details organizational behavior and human decision processes., $120,15-23$. 
Elgaaied-Gambier, L., Monnot, E., \& Reniou, F. (2018). Using descriptive norm appeals effectively to promote green behavior. Journal of Business Research, 82, 179-191.

Hayes, A. F., Little, T. D. (2018). Introduction to mediation, moderation, and conditional process analysis: a regression-based approach.

Hendry, L. (2018) Slow start to united way support. The intelligencer. https://www.intelligencer. ca/news/local-news/slow-start-to-united-way-support. Accessed may 9th 2020.

Higgins, E. T. (1997). Beyond Pleasure and Pain. American Psychologist, 52, 1280-1300.

Higgins, E. T., Roney, C. J. R., Crowe, E., \& Hymes, C. (1994). Ideal versus ought predilections for approach and avoidance: distinct self-regulatory systems. Journal of Personality and Social Psychology, 66, 276286.

Leary, M. R. (2007). Motivational and emotional aspects of the self. Annual Review of Psychology, 58, 317344. https://doi.org/10.1146/annurev.psych.58.110405.085658.

Lee, S., Winterich, K. P., \& Ross Jr., W. T. (2014). I'm moral, but I won't help you: the distinct roles of empathy and justice in donations. Journal of Consumer Research, 41, 678-696.

Liu, W., \& Aaker, J. (2008). The happiness of giving: the time-ask effect. Journal of Consumer Research, 35 , 543-557.

Lynn, M., \& Harris, J. (1997). Individual differences in the pursuit of self-uniqueness through consumption. Journal of Applied Social Psychology, 27, 1861-1883. https://doi.org/10.1111/j.1559-1816.1997. tb01629.x.

Mishra, H., Mishra, A., \& Nayakankuppam, D. (2010). How Salary Receipt Affects Consumers' Regulatory Motivations and Product Preferences. Journal of Marketing, 74, 93-103.

Newell, S. J., \& Goldsmith, R. E. (2001). The development of a scale to measure perceived corporate credibility. Journal of Business Research, 52, 235-247.

Sharma, E., \& Morwitz, V. G. (2016). Saving the masses: the impact of perceived efficacy on charitable giving to single vs. multiple beneficiaries organizational behavior and human decision processes., 135, 45-54.

Xie, C., \& Bagozzi, R. P. (2014). The Role of Moral Emotions and Consumer Values and Traits in the Decision to Support Nonprofits. Journal of Nonprofit \& Public Sector Marketing, 26, 290-311.

Publisher's note Springer Nature remains neutral with regard to jurisdictional claims in published maps and institutional affiliations.

\section{Affiliations}

\section{Nhat Quang Le ${ }^{1} \cdot$ Magne Supphellen $^{2} \cdot$ Richard P. Bagozzi $^{3}$}

1 Department of Strategy and Management/DIG, Norwegian School of Economics, Helleveien 30, 5045 Bergen, Norway

2 Department of Strategy and Management, Norwegian School of Economics, Helleveien 30, 5045 Bergen, Norway

3 Ross School of Business, University of Michigan, 701 Tappan Street, Ann Arbor, MI 48109-1234, USA 